\title{
From the cage to the wild: Introductions of Psittaciformes to Puerto Rico
}

\author{
Wilfredo Falcón Corresp., 1, 2,3 , Raymond L Tremblay ${ }^{1,2}$ \\ 1 Department of Biology, University of Puerto Rico at Humacao, Humacao, Puerto Rico, United States of America \\ 2 Center for Applied Tropical Ecology and Conservation, University of Puerto Rico, Río Piedras, Puerto Rico, United States of America \\ 3 Bureau of Research and Conservation of Habitats and Biodiversity, Puerto Rico Department of Natural and Environmental Resources, San Juan, Puerto \\ Rico, United States of America \\ Corresponding Author: Wilfredo Falcón \\ Email address: wfalcon.research@gmail.com
}

Introduced psittacine birds can become highly invasive. In this study, we assessed invasions of Psittaciformes in Puerto Rico. We reviewed the literature, public databases, citizen science records, and performed in situ population surveys across the island to determine the historical and current status and distribution of psittacine species. We used count data from Ebird to determine population trends. For species whose populations were increasing, we modelled their potential distribution using niche modeling techniques. We found 46 Psittaciformes in Puerto Rico, of which $26 \%$ are only present as pets, at least 29 species have been reported in the wild, and of those, there is evidence that at least 12 species are breeding. Our results indicate that most introduced species which have been detected as established still persist, although mostly in localized areas and small populations. Clear evidence of invasiveness was found for Brotogeris versicolurus and Myiopsitta monachus, which have greatly expanded their range in recent years. Psittacara erythrogenys and Eupsittacula canicularis also showed population increases, although to a lesser degree. The niche models predicted suitable areas for the four species, and also indicate the potential for range expansion. We discuss the factors leading to invasion success, assess the potential impacts, and we discuss possible management strategies and research prospects. 


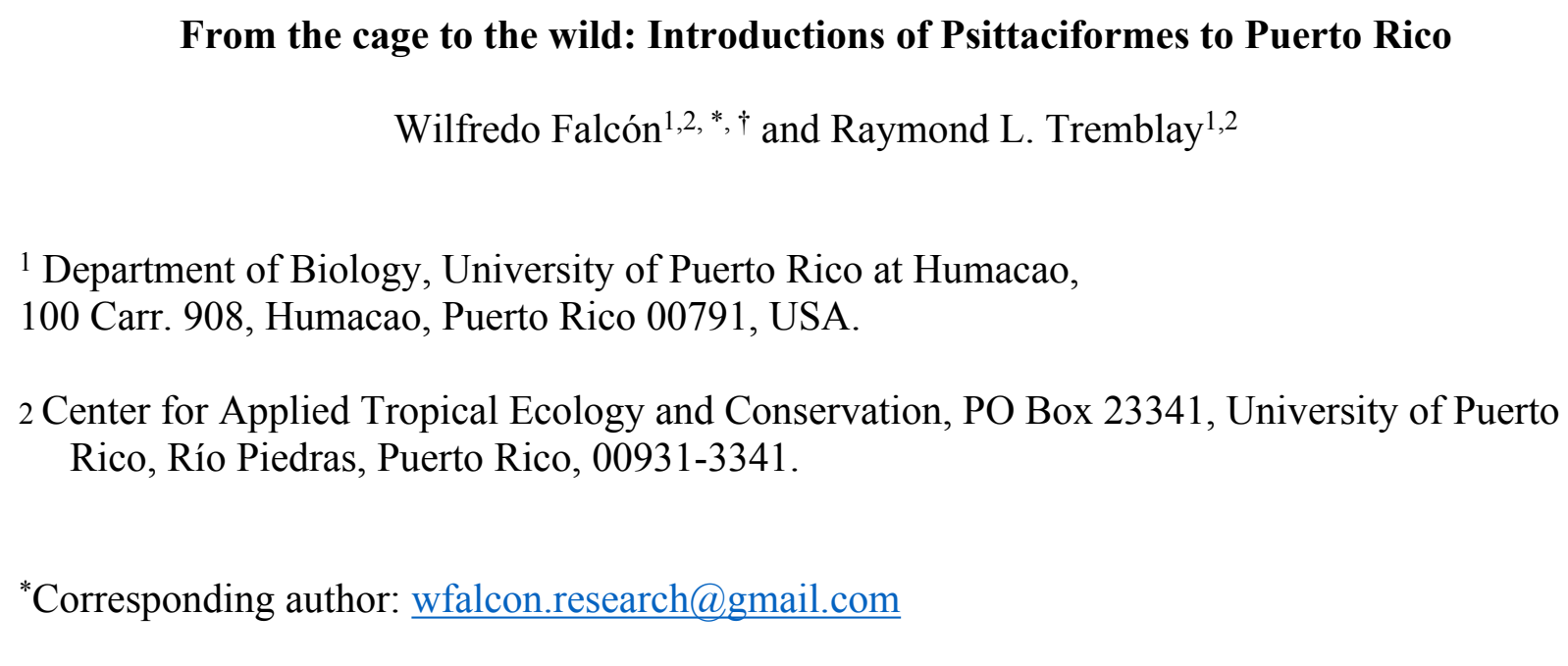

\section{From the cage to the wild: Introductions of Psittaciformes to Puerto Rico}

Wilfredo Falcón ${ }^{1,2, *}{ }^{*} \dagger$ and Raymond L. Tremblay ${ }^{1,2}$

${ }^{1}$ Department of Biology, University of Puerto Rico at Humacao,

100 Carr. 908, Humacao, Puerto Rico 00791, USA.

2 Center for Applied Tropical Ecology and Conservation, PO Box 23341, University of Puerto Rico, Río Piedras, Puerto Rico, 00931-3341.

*Corresponding author: wfalcon.research@gmail.com

Corresponding author. walcon.research@gnail.com 


\section{Abstract}

42 Introduced psittacine birds can become highly invasive. In this study, we assessed invasions of

43 Psittaciformes in Puerto Rico. We reviewed the literature, public databases, citizen science

44 records, and performed in situ population surveys across the island to determine the historical

45 and current status and distribution of psittacine species. We used count data from Ebird to

46 determine population trends. For species whose populations were increasing, we modelled their

47 potential distribution using niche modeling techniques. We found 46 Psittaciformes in Puerto

48 Rico, of which $26 \%$ are only present as pets, at least 29 species have been reported in the wild,

49 and of those, there is evidence that at least 12 species are breeding. Our results indicate that most

50 introduced species which have been detected as established still persist, although mostly in

51 localized areas and small populations. Clear evidence of invasiveness was found for Brotogeris

52 versicolurus and Myiopsitta monachus, which have greatly expanded their range in recent years.

53 Psittacara erythrogenys and Eupsittacula canicularis also showed population increases, although

54 to a lesser degree. The niche models predicted suitable areas for the four species, and also

55 indicate the potential for range expansion. We discuss the factors leading to invasion success,

56 assess the potential impacts, and we discuss possible management strategies and research

57 prospects. 


\section{Introduction}

60 With the globalization of economies, the rate of species introductions has risen considerably to

61 the extent that the shifts in species distributions and the reorganization of biodiversity are now

62 considered a signature of the Anthropocene (Seebens et al., 2017). In parallel, invasive species

63 have gained broad attention from ecologists, government agencies and the public due to the

64 potential and realized negative impacts on economies, human health, native species, and ecosystem services (Sanders et al., 2003; Mooney, 2005; Davis, 2009; Lockwood et al., 2013).

One of the factors that most contributed to the establishment of non-native species in recent history has been the pet trade (Smith et al., 2009).

Psittaciformes are among the exotics species most commonly sold as pets, with two-thirds

of the known species in this group known to occur in the pet trade (parrots, conures and cockatoos) (Cassey et al., 2004b). In the 1990's the global pet trade in Psittaciformes generated USD \$1.4 billion and was largely supplied by four million wild-caught birds (Thomsen et al., 1992). Four general modes of introductions to native habitats have been identified for parrots: releases by traders due to oversupply or legal complications (Forshaw, 1973; Robinson, 2001), or the accidental or intentional releases by pet owners (Blackburn, et al., 2009).

Two thirds of successful avian introductions have been on islands (Blackburn et al., 2009), however, it should be noted that most unsuccessful introductions have not been documented

77 (Mori et al., 2014). In Puerto Rico, many species of Psittaciformes have been imported for sale as pets, especially since the 1950 's, and by 2000, eight had likely become established (PérezRivera, 1985; Raffaele, 1989; Camacho-Rodríguez et al., 1999; Oberle, 2000). As with any exotic, invasive species, local, state, and federal agencies are concerned with the possible effects

81 that these species may have on ecosystem processes and populations of indigenous species. Of 
82 particular concern in Puerto Rico is the US Federal Government and World Conservation Union

83 listed, critically endangered species, the endemic Puerto Rican amazon, Amazona vittata (Snyder 84 et al. 2007).

85 In this study, we review the introduction and persistence of Psittaciformes in Puerto Rico,

86 by evaluating their historic and present distributions. In addition, we assess population trends,

87 and present the predicted distribution of the most successful psittacine species on the island using

88 niche modelling techniques. Finally, we identify possible factors that may contribute to the

89 successful establishment of Psittaciformes in Puerto Rico and discuss our results in the context of

90 potential impacts, management and prospects.

92 Materials and Methods

93 Members of the Psittaciformes, which comprise about 393 species in 92 genera that include

94 macaws, cockatoos, parrots, and conures, are mostly pantropical, although some species inhabit

95 temperate areas in the southern hemisphere (Juniper \& Parr, 1998; Forshaw, 2010). They are

96 considered one of the most endangered groups of birds in the world, and threats include trapping

97 for trade, habitat destruction and hunting (Snyder et al., 2000).

99 Historical and current status of Psittaciformes

100 To assess the historical introductions of Psittaciformes to Puerto Rico, and their current status,

101 we surveyed historical reports on the distribution of the species (Forshaw, 1973; Pérez-Rivera \&

102 Vélez-Miranda, 1980; Pérez-Rivera, 1985; Pérez-Rivera et al., 1985; Raffaele, 1989; Camacho-

103 Rodríguez et al., 1999; Oberle, 2000). We also recorded species occurrences based on

104 observations made during 2013-2017. In addition, we surveyed the E-bird (http://ebird.com/) 
105 online database, which contain records from amateurs and professional ornithologists.

106 Well curated open access observational data, such as that available through Ebird, provides

107 a base for evidence-based research, conservation and management actions in a cost-effective

108 way, especially in the absence of scientifically-derived data (Sullivan et al., 2017). Still, these

109 data are not free of biases. To collect data, Ebird employs relatively unstructured protocols with

110 the aims of attracting a large number of observers (Hochachka et al., 2012). As a result, these

111 protocols do not control for several sources of error during the data collection process, which

112 need to be accounted for during data manipulation and analysis, (e.g., variation in the

113 observation process such as duration of observation periods, distances travelled and time of day,

114 can affect the probability of detecting birds; Sullivan et al., 2014; 2017). After data collection,

115 the results that become part of the data products accessible through Ebird are validated through

116 automated and human screening of the observations (Sullivan et al., 2017). For example, escaped

117 pets are likely part of the records contained in Ebird, which can bias the distribution models (see

118 below). Nonetheless, we assume that sampling effort is equal across years in our estimation of

119 sighting trends, which is not likely the case. This could bias the estimation of population increase

120 based on sighting trends. Therefore, our results must be interpreted within the boundaries of

121 these limitations.

122 Searches were also conducted on online local birding groups for photographic records

123 using the search terms 'parrot', 'parakeet', 'macaw', 'cockatoo' in English and Spanish. The

124 local groups included: Aves de Puerto Rico (https://www.facebook.com/avesdepuertoricoFelPe/),

125 the Puerto Rico Ornithological Society

126 (https://www.facebook.com/sociedadornitologicapuertorriquena/), Bird Photographers of Puerto

127 Rico (https://www.facebook.com/groups/615958701756859/), and Biodiversidad de Puerto Rico 
128 (https://www.facebook.com/groups/PRNatural/). This was done between November-December

1292017 (see electronic supplementary information S1 for the origin of the data). To identify species

130 sold as pets we visited pet stores, mainly in the Metropolitan Area of San Juan, and the pet

131 section of local online classified ads Clasificados Online (www.clasificadosonline.com).

132 Moreover, the online databases Ebird, CABI Invasive Species Compendium

133 (https://www.cabi.org/isc) and the Global Invasive Species Database

134 (http://www.iucngisd.org/gisd) were used to assess the "invasiveness" of species of

135 Psittaciformes have reached in their non-native range (outside Puerto Rico) using the

136 categorization scheme of Blackburn et al. (2011; see Table 1). The latter scheme was also used to

137 classify the invasive status of introduced psittacines in Puerto Rico. We used Forshaw (2010) for

138 taxonomical classification and common names of Psittaciformes, the native distribution, and

139 include any classification changes according to del Hoyo et al. (2014). The IUCN Red List (ver.

1403.1 ; www.iucnredlist.org) was used to assess the conservation status for each species, population

141 trends in their native range, and possible threats or reasons for population increase.

142

143 Sighting trends of Psittaciformes in Puerto Rico

144 To assess the sighting trends of Psittaciformes in Puerto Rico, we used observation count reports

145 from Ebird for each species (see electronic supplementary information S2 for count data). We

146 calculated the mean number of birds counted per municipality/year (where they have been

147 observed), and then summed the mean number of birds per municipality to obtain the island-

148 wide counts per year. Only species with at least 20 records were included in the subsequent 149 analyses.

150

151 Distribution of Psittaciformes in Puerto Rico 
152 We assess the current distribution of the introduced psittacines by surveying Ebird for geo-

153 referenced records (see electronic supplementary information S2 for location records). After

154 identifying psittacine species whose sighting trends showed an increase, we employed niche-

155 modeling techniques following the methodology used by Falcón et al. $(2012 ; 2013)$. Species

156 distribution models were constructed with the Maximum Entropy Method (MaxEnt ver. 3.4.1;

157 Phillips, Anderson \& Schapire, 2006; Phillips, Dudík \& Schapire, 2017), which is a learning

158 machine method that uses presence only data in combination with predictive variables to model a

159 species' geographic distribution. Several studies have demonstrated that MaxEnt performs well

160 at predicting species geographic distributions, and it has shown better performance and

161 predictive ability when compared to other niche-modeling techniques (e.g., Duque-Lazo et al.,

162 2016; Bueno et al., 2017). We used climatic layers obtained from WorldClim (ver. 2) as

163 predictive variables in our model (http://worldclim.org/version2; Fick \& Hijmans, 2017). These

164 variables are derived from monthly temperature and rainfall values that represent annual trends,

165 seasonality and extreme or limiting environmental factors (Hijmans et al., 2005). For our models,

166 we selected temperature seasonality (BIO4), maximum temperature of the warmest month

167 (BIO5), minimum temperature of the coldest month (BIO6), precipitation of the wettest month

168 (BIO13), precipitation of the driest month (BIO14) and precipitation seasonality (BIO15) as

169 climatic variables because they represent the extreme limiting climatic factors and their

170 variation. The calibration area was defined as the smallest rectangle that encompassed all the

171 location records that we used for the model plus $10 \mathrm{~km}$, and restricted to the subtropics in the

172 Americas (minimum and maximum latitude -30-30 $0^{\circ}$ Corlett, 2013). For presence records, we

173 used the geo-referenced and validated locations that we obtained from the different sources listed

174 above, after eliminating duplicates and setting a minimum distance of $1.5 \mathrm{~km}$ between 
175 occurrence records (to prevent model overfitting due to similar climatic conditions of adjacent

176 points). We randomly selected $20 \%$ of the points to test the performance of the model and

177 performed 10 replicates. To evaluate the performance of the model, we used the AUC statistics

178 (area under the receiver operating characteristic curve), which provides a single measure of the

179 model performance (Phillips et al., 2006). Models that have an excellent predictive performance

180 have AUC values $>0.90,0.80-0.90$ are considered to have good predictive performance, while

181 models with AUC values < 0.70 are considered poor (Swets, 1988; Manel et al., 2001; Franklin,

182 2010). To determine the presence-absence threshold, we used the Maximum Training Specificity

183 plus Sensitivity threshold, which minimizes the mean of the error rate for positive and negative

184 observations (Manel et al., 2001; Freeman \& Moisen, 2008), and performs better than other

185 thresholds in providing accurate presence predictions (Liu et al., 2005; Jiménez-Valverde \&

186 Lobo, 2007; Freeman \& Moisen, 2008).

187

188

Habitat association of Psittaciformes in Puerto Rico

189 To characterize the habitat used by non-indigenous psittacines whose populations are increasing,

190 we extracted land cover data from the Puerto Rico Land Cover Map (Gould et al., 2007) using

191 the occurrence locations obtained from Ebird. We restricted this analysis to occurrence records

192 from 2000-2017 and assume no land cover changes after the map was developed (mostly from

193 satellite images from 2001-2003). We simplified the land cover categorization into 'urban'

194 'forests', 'pastures', 'wetlands' and 'other' habitats (see electronic supplementary information S3

195 for original and simplified classifications).

196

197 Statistical analyses and data visualization

198 We performed all data pre-processing, and obtained summary statistics and visualizations using 
199 R ver. 3.3.3 (R Core Team, 2017), and packages 'ggplot2' (Wickham, 2016), 'raster' (Hijmans,

200 2017), 'zoo' (Zeileis \& Grothendieck, 2005), 'plyr' (Wickham, 2011), and the output from

201 MaxEnt. We mapped occurrence records and visualized distribution results using QGIS ver.

202 2.18.14-Las Palmas de G. C. (QGIS Development Team, 2017). To test whether the observed

203 habitat used by the species follows the proportion of the available habitat, we compared the

204 observed habitat used by each species to the available habitats throughout Puerto Rico (extracted

205 from the Land Cover Map) using Chi-square goodness-of-fit analysis (Neu, Byers \& Peek, 1974)

206 and computed the $p$-values for a Monte Carlo test (Hope, 1968).

207

208 Results

209 Historical and current status of Psittaciformes

210 We found historical records for 18 species of Psittaciformes reported by the year 2000, with

211 eight of those breeding. At least 46 psittacine species are now present on the island (Table 1; Fig.

212 1), of which $24 \%$ are only found in the pet trade, $48 \%$ have been observed in the wild (present),

213 but not known to be breeding (established), and 28\% are established (naturalized) and known to

214 have bred or are currently breeding (Table 1). At least $85 \%$ of the species are currently available

215 for sale in the pet trade. Of the 46 species of Psittaciformes found in Puerto Rico, at least $63 \%$

216 have been reported in the wild elsewhere (but it is unknown whether they are breeding in these

217 new environments), and $26 \%$ are considered as established or invasive (i.e., breeding outside

218 their native range and expanding their range).

219

220 Sighting trends of Psittaciformes in Puerto Rico

221 We found sufficient reports to calculate the island-wide sighting trends for 10 species of 
222 Psittaciformes in Puerto Rico (Fig. 2). Four species exhibited population increase, three species

223 showed stable populations, and three species exhibited population decrease. For the rest of the

224 species, the count numbers were too low and/or temporal resolution was too short to calculate

225 trends. Of the species with growing populations, the white-winged parakeet (Brotogeris

226 versicolurus) showed the largest population increase, followed by the monk parakeet (Myiopsitta

227 monachus), the red-masked conure (Psittacara (Aratinga) erythrogenys) and the orange-fronted

228 parakeet (Eupsittula canicularis; Fig. 2). The orange winged amazon (Amazona amazonica)

229 showed a population increase and later stabilized, while the white-crested cockatoo (Cacatua

230 alba) showed a stable population trend, albeit with low numbers. The blue-and-yellow macaw

231 (Ara aranaura) exhibited a decrease from 1996 to 2002 (with up to 22 individuals reported) in

232 the Metropolitan Area of San Juan, and later recovered and stabilized with about 14 individuals.

233 The green-cheeked amazon (Amazona viridigenalis) showed a steep decrease after reaching a

234 total of 53 individuals per mean count/municipality/year, with low counts after 2006. Similar

235 trends were observed in the white-fronted amazon (A. albifrons), but in much lower numbers.

236 Finally, the rose-ringed parakeet (Psittacula krameri) showed a sustained decrease from a

237 maximum of 12 individuals which was reported in 2011.

238 The orange-winged amazons exhibited an increase in sightings since the 1990's, and by

239 2014, the population seemed to be stabilized. The maximum number of individuals reported is

24039 , but there is a population roosting in the municipality of Morovis with over 100 individuals

241 (not included in the count data; J. Salgado Vélez, pers. comm.). Moreover, the orange-winged

242 amazons are the most widespread of the amazon parrots in Puerto Rico. The blue-and-yellow

243 macaws apparently experienced a population decline in the Metropolitan Area of San Juan, and

244 later increased and stabilized. Furthermore, a population of at least 15 individuals is breeding in 
245 the municipality of Orocovis, $\sim 29 \mathrm{~km}$ away from the other population (not included in count

246 data), and some have been sighted in Cabo Rojo (southwest Puerto Rico island). The sighting

247 trends of the white-crested cockatoo indicate that the population is small but stable ( $2-15$

248 individuals) and localized in the adjacent municipalities of Bayamón and Guaynabo in the

249 Metropolitan Area. Other species exhibited sighting declines after an initial increase. The green-

250 fronted amazon has two reported populations; one in the municipality of Mayagüez (west) with

251 up to 10 individuals recorded, and one in the municipality of Salinas (southeast) with up to 30

252 individuals recorded. In the case of the white-fronted amazon, which is restricted to Mayagüez, it

253 exhibited a reduction in sightings, from up to 11 individuals in 2011 , to $1-2$ individuals in recent

254 years. The rose-ringed parakeet is currently uncommon, but in 2012 at least 12 individuals were

255 sighted in Aguadilla (northwest Puerto Rico).

256

257 Habitat association of Psittaciformes in Puerto Rico

258 All four species of Psittaciformes whose populations were increasing (white-winged parakeets,

259 monk parakeets, red-masked conure and the orange-fronted parakeet) exhibited similar habitat

260 use; $66 \%$ of the occurrences were located in urban areas (33\% in high density and $33 \%$ in low

261 density urban areas) while $33 \%$ of the other occurrences were located in forested areas near

262 urban areas. The observed habitat used differed from the expected habitat available for all four

263 species $(p<0.001$ in all cases).

Distribution of Psittaciformes in Puerto Rico

266 Overall, we obtained 6,905 locality records for 26 species of Psittaciformes in the wild that

267 spanned from 1960 to 2017 (in Ebird; see electronic supplementary information S1 for detailed 
268 species-specific results and S2 for location records). Moreover, we obtained 279 sighting records

269 for 10 species from local groups (see electronic supplementary information S4 for links to

270 species-specific reports). Sightings and reports of Psittaciformes in Puerto Rico practically cover

271 the whole island and are especially dense in coastal and highly (human) populated areas (Fig. 3),

272 but the geographic extent of the distribution varies by species (see electronic supplementary

273 information S5 for the distribution of locations for each species reported in the island).

274 More specifically, we obtained 2,520 occurrences for the white-winged parakeet. Historic

275 reports on the distribution of B. versicolurus show that parakeets were present in Luquillo (east)

276 in small numbers by the 1960's (Kepler in Bond 1971). Moreover, a small population was found

277 breeding in the municipality of Naguabo (east) and about 360 individuals were reported in

278 Guaynabo (San Juan metro area) by 1985, where the San Patricio population is presently located

279 (Pérez-Rivera et al., 1985). Furthermore, the only other historic records are from the population

280 in San Germán (southwest), which was estimated at 800 individuals by 1995 (Camacho-

281 Rodríguez et al, 1999). Since then, the parakeet populations have expanded significantly

282 throughout the island, especially to coastal and urban/suburban areas, but occasionally they have

283 been observed in the central mountainous regions (Fig. 4a).

284 To predict the potential distribution of the psittacine species whose populations are

285 increasing in Puerto Rico, we obtained 106,493 occurrence records from their native and

286 invasive range (including Puerto Rico; see electronic supplementary information S2). Our

287 models performed good to excellent, with test AUC values ranging from 0.82-0.94 (Table 2),

288 and the presence records for the four species are within the predicted distribution of their native

289 ranges, indicating a good model fit. Furthermore, the models predicted suitable areas for all four

290 species in Puerto Rico (Fig. 4). 
The predicted distribution for the white-winged parakeet in Puerto Rico showed the highest

292 suitable areas in the north-central part of the island, but also included other coastal areas. Only in

293 the central and central-west part of the island, where the Central Cordillera occurs, did MaxEnt

294 predict unsuitable areas for the species. In general, the white-winged parakeet occupies virtually

295 all areas with the highest suitability. Similar areas were predicted with suitable climatic

296 conditions for the monk parakeet, although there are areas in the west of the island predicted as

297 unsuitable where the monk parakeet has been reported. The models also predicted suitable areas

298 for the red-masked conure and the orange-fronted parakeet, some of which they occupy. Both

299 species have lower predicted climatic suitability than white-winged and monk parakeets, and the

300 orange-fronted parakeet has a smaller predicted suitable area than the other species. In general,

301 our models predicted suitable areas outside the current range of all four species, indicating the

302 possibility for further range expansion.

303

304 Discussion

305 In this study, we assessed the status of non-native Psittaciformes in Puerto Rico. All have been

306 introduced via the pet trade, and nearly half of the 46 psittacine species present on the island

307 have been observed in the wild. Historical records indicate that once established and breeding,

308 most are persistent.

309 Observations on flock size and sighting trends of Psittaciformes in Puerto Rico indicate

310 that the different species are experiencing different dynamics. White-winged and monk parakeets

311 are the only two species that appear to be growing exponentially. Moreover, for the white-

312 winged parakeet, the island-wide sum of the mean counts per municipality shows a substantial

313 increase of birds across Puerto Rico, indicating range expansion and exhibiting a lag-phase 
314 followed by exponential growth. This is consistent with the patterns of increase and population

315 growth rates in two of the largest populations of white-winged parakeets in Puerto Rico (Falcón

316 and Tremblay, unpubl.). Similarly, records for the monk parakeets started in 1979 throughout

317 coastal and densely populated (humans) areas (mainly San Juan and Ponce), and by 1987, flocks

318 of up to 30 individuals were observed. By the late 1990's sightings outside these two

319 municipalities started and became more common throughout the island as time passed probably

320 as a result of population growth and range expansion.

321 In general, invasive Psittaciformes are strongly associated with urban areas (e.g., Avery \&

322 Shiels, 2017) and those in Puerto Rico are no exception. These birds are most commonly sighted

323 along coastal regions of the island, particularly areas with the highest human population

324 densities, as in the metropolitan area of San Juan. Nevertheless, the location and the extent of the 325 geographic distribution of Psittaciformes in Puerto Rico varies among species. Psittacine species

326 whose populations are increasing in Puerto Rico occur in similar habitats and more frequently in

327 urban rather than forested areas. Yet even those wooded areas are close to urban centers where

328 they are known as 'novel' forests for their mixture of native and invasive species (Lugo, 2004;

329 Gould et al., 2007)..

330 Populations of the most recorded and widespread species, monk and white-winged

331 parakeets, are increasing, and their current distributions coincide with areas predicted to be

332 climatically suitable. Moreover, suitable areas are present outside where these different species

333 occur, indicating the potential for continued range expansion.

334 When modelling the potential distribution of invasive species, especially when performing

335 risk analyses, a more complete envelope of conditions (climatic in our case) in which the species

336 can survive and reproduce can be attained by including a combination of presence records from 
337 both the native and invasive range (e.g., (Steiner et al., 2008; Falcón et al., 2012; 2013). Despite

338 doing so in our analyses, and having models with good predictive scores (high AUC values),

339 some presence records fell out of the predicted distributions, even for the most abundant and

340 widespread species (e.g., locations in the central-western parts of the island). Several factors may

341 have contributed to this. First, some records may reflect locations where the species are only

342 transient or represent locations of recently escaped pets. Secondly, inherent uncertainties and

343 error are associated with the models; AUC values, while good to excellent (0.82-0.94), were not

344 perfect. Nevertheless, the models predict habitat suitability for all locations where we know that

345 the different species reside and reproduce (based on our surveys).

346 Perhaps the most important factor promoting the success of Psittaciformes outside their

347 native range is the sheer number of individuals that were and are available through the pet trade.

348 Invasion success for exotic bird species is positively influenced by the number of individuals

349 available on the market (Carrete \& Tella, 2008). Species most commonly found in captivity and

350 those that are inexpensive, have a higher probability of being introduced into the wild (Robinson,

351 2001; Cassey et al., 2004b; Blackburn et al., 2009). In general, among bird species,

352 Psittaciformes have a high probability of transport and introduction outside their native range

353 (Lockwood, 1999; Lockwood et al., 2000; Blackburn \& Duncan, 2001; Duncan et al., 2006),

354 being traded up to 14 times more often than other avian orders (Bush et al., 2014). Moreover,

355 parrots in general have a wide diet breath, and research suggests that diet breath and migratory

356 tendencies can explain the success of established exotic populations of parrots (Cassey et al.,

357 2004a). Consequently, 10-16\% of all parrot species have established exotic populations around

358 the world (Cassey et al., 2004b; Menchetti \& Mori, 2014). Parrots have been and continue to be

359 popular pets in Puerto Rico, so it is likely that propagule pressure has played a role in the 
360 introduction of psittacines on the island. Moreover, their wide diet breath and their affinity for

361 urban habitats may have helped them establish wild populations. This seems to be the case with

362 the white-winged parakeets in Puerto Rico, which remain highly traded on the island (Falcón and

363 Tremblay, unpubl.).

364 As with any introduced invasive species, there are concerns over the possible negative

365 impacts that exotic parrots may have on the economy, ecosystem services, and populations of

366 native species (Pérez-Rivera \& Vélez-Miranda, 1980; Menchetti \& Mori, 2014). These include

367 damage to crops, damage to the electrical infrastructure, transmission of diseases, competition,

368 and hybridization. However, other than warnings about potential impacts, no studies have

369 reported negative impacts by Psittaciformes on ecosystem functions, or specific species in Puerto

370 Rico. Damage to crops is perhaps the biggest negative impact that parrots cause in both their

371 native and introduced range, with substantial economic losses (e.g., González, 2003). However,

372 parrots in Puerto Rico seem to be associated with urban areas and heavily rely on food resources

373 in these areas as well as from nearby novel forests, and we found no reports on crop damage. In

374 Florida (USA), monk parakeets have been reported to cause electric shortages while building

375 nests in electric towers, costing as much as USD 585,000 for repairs (Avery et al., 2006), but

376 there is no evidence of that occurring in Puerto Rico. Moreover, wild and captive Psittaciformes

377 are known vectors of avian and diseases and parasites, and also human diseases (Clark et al.,

378 1988; Orosz et al., 1992; Magnino et al., 1996; Mase et al., 2001; Azevedo, 2014; Done \&

379 Tamura, 2014; Briceno et al., 2017). We found an unidentified species of mite (probably

380 Pararalichus) on white-winged parakeets. Pararalichus mites have been reported on the white-

381 winged parakeet in its native range, along with Aralichus cribiformes and Echinofemur sp. and

382 Rhytidelasma sp. (Atyeo, 1989). In most cases, transfer of mites occurs by physical contact 
383 between conspecifics, but there are cases of inter-species transfer (Dabert \& Mironov, 1999;

384 Hernandes et al., 2016). Although there are concerns that mites may be vectors for diseases

385 among parrots, most feather mites are considered ecto-commensals and feed on the oils produced

386 by the birds (Blanco et al., 2001). Competition for nesting cavities is a major cause of concern

387 because there are native species which depend on this scarce resource, and psittacine secondary

388 cavity nesters can be aggressive competitors (Snyder et al., 2007; Strubbe \& Matthysen, 2009a;

389 Orchan et al., 2012; Mori et al., 2017). Currently, populations of non-indigenous cavity nesters

390 (e.g., Amazona spp. and rose-ringed parakeets) are relatively low, whereas the most successful

391 psittacine species in Puerto Rico build their own nests. Finally, hybridization with congenerics is

392 considered a latent threat to the endemic and endangered Puerto Rican amazon. For example,

393 Amazona oratrix and A. aestiva are known to hybridize in sympatric regions of their introduced

394 ranges; Martens et al., 2013). Based on the distribution of non-indigenous Amazona spp. in

395 Puerto Rico, hybridization with the Puerto Rican amazon is unlikely at the moment.

396 Nonetheless, it is a future possibility as both endemic and introduced populations continue to

397 grow and expand their ranges. Thus, we have not yet uncovered any negative impacts by

398 psitticines on the island, but the potential exists, which merits monitoring.

399 Introduced psittacines may actually have positive impacts by filling niches once occupied

400 by Puerto Rico's indigenous parrots, which were much more common in the past and inhabited

401 many of the areas now occupied by exotic species. In fact, the extinct Puerto Rican parakeet

402 (Psittacara maugei) was so abundant and widespread that it was, in part, hunted down to

403 extinction because of the damage it caused to the agricultural sector (Olson, 2015), as was the

404 fate of the Carolina parakeet, Corunopsis carolinensis (Saikku, 1990).

405 Of course, pre-colombian habitats of the Puerto Rican amazon have since been heavily 
406 modified by human activities. The forests that now exist are considered 'novel' communities

407 (Lugo, 2004), secondary forests with a mix of native and introduced species of plants and

408 animals. Similar to the island's exotic finches (Rafaelle, 1989), non-native psittacine species are

409 mainly occupying communities which did not exist in the recent past. It remains to be seen

410 whether or not A. vittata will find these communities suitable.

411 As in other psittacine species, perhaps one of the most important functions performed by

412 indigenous parrots in Puerto Rico were seed predation and seed dispersal. Some parrots are

413 known to be both seed predators and dispersers (Norconk, Grafton \& Conklin Brittain, 1998;

414 Francisco et al., 2002; Blanco et al., 2015; 2016; Blanco et al., 2017), and both seed predation

415 and seed dispersal have important implications for ecosystems dynamics worldwide, and help

416 regulate plant recruitment, competition, and population structure (Howe \& Smallwood, 1982;

417 Hamrick et al., 1993; Nathan \& Muller-Landau, 2000). Unlike other birds, parrots have

418 specialized bills that allows them to access resources, such as hard seeds, that are often not

419 available to other animals, and they often destroy seeds in the wild. For example, the white-

420 winged parakeet is a seed predator of the Panama tree (Sterculia apetala), an introduced species

421 in Puerto Rico. But they also eat seeds of native species such as the pink trumpet tree (Tabebuia

422 heterophylla). Likewise, blue-and-yellow macaws consume seeds of mahogany, Swietenia spp.,

423 which are exotic trees whose seeds are too large for other species of birds. On the other hand, as

424 generalist frugivores, parrots also act as seed dispersers via endozoochory (Blanco et al., 2016).

425 For example, white-winged parakeets are known to disperse Ficus spp., which have fruits

426 containing numerous small, hard-seeds (W. Falcón, pers. obs.). Little is known of frugivory and

427 seed predation by parrots in their native ranges, and we are unaware of any such studies on

428 introduced psittacines. Future research should focus on the ecological role of introduced 
429 psittacines to assess whether or not impacts occur, positive or negative.

430 Currently, no species of Psittaciformes is considered illegal in Puerto Rico by the Puerto

431 Rico Department of Natural and Environmental Resources (DNER; Departamento de Recursos

432 Naturales y Ambientales de Puerto Rico, 2003). Trapping of exotic birds established in Puerto

433 Rico is allowed by the DNER for exportation only, and the sale in local markets is prohibited.

434 The most commonly trapped bird was the white-winged parakeet; however, the number of

435 individuals trapped is rarely reported and no aspect of the exportation process is revealed. We

436 recommend that protocols should be modified to obtain such information which would inform

437 management strategies.

438 Prevention can be the most cost-effective way of dealing with invasive species. Although

439 selling some of the wild trapped species of parrots in the local pet market is illegal, it is common

440 to find people selling them, especially on the internet. Particularly common are budgerigars

441 (Melopsittacus undulatus), lovebirds (Agapornis spp.), white-winged parakeets and monk

442 parakeets. The rose-ringed parakeet is gaining popularity and it is relatively easy to acquire them.

443 It is highly invasive elsewhere, and has caused negative ecological impacts (Butler, 2003;

444 Strubbe \& Matthysen, 2009a,b; Kumschick \& Nentwig, 2010; Newson et al., 2011; Sa et al.,

445 2014; Le Louarn et al., 2016). Therefore, special attention should be given to this species, and

446 others that have invasiveness potential. We recommend that management agencies prohibit

447 and/or limit the sale and possession of psittacine species that are prone to establish outside their

448 native range. Propagule pressure may be reduced by focusing on the trade of Psittaciformes (and

449 other species). Specifically, we proposed that DNER revise and update Article 7 in the "New

450 Regulation to Govern the Conservation and Management of Wildlife, Exotic Species and

451 Hunting in the Commonwealth of Puerto Rico", which deals with exotic species (Departamento 
452 de Recursos Naturales y Ambientales de Puerto Rico, 2003).

453 Several strategies for the control and management of established psittacines are available

454 should they become necessary and/or desirable. Public education programs could be

455 implemented to illustrate the importance of breeding controls and the potential negative effects

456 of releasing exotic animals into the wild. When direct management is necessary, there are three

457 options: 1) trapping and exporting birds, 2) birth control chemosterilants such as Diazacon ${ }^{\mathrm{TM}}$

458 (Yoder et al., 2007; Avery et al., 2008; Lambert et al., 2010), and 3) culling (lethal). Control

459 efforts, especially lethal ones, may be hindered by the public, who usually protest these actions

460 as parrots have a high aesthetic value (Avery \& Tillman, 2005).

461 Catastrophic events may severely alter population sizes of both native and invasive species.

462 In late 2017, Hurricane María, a category four hurricane, drastically altered the entire island of

463 Puerto Rico, and undoubtedly caused negative impacts on the parrot populations in the island.

464 Dozens of dead white-winged parakeets were observed around a recent roost located in Río

465 Piedras (municipality of San Juan; Fig. 1f), and at least one blue-and-yellow macaw was found

466 dead in Guaynabo (part of the Greater San Juan metropolitan area). Despite this, numerous

467 flocks of parakeets and at least eight macaws were seen after the hurricane, so a proportion of

468 individuals of these species survived. Even the endemic Puerto Rican amazon suffered very high

469 hurricane-related losses in the east of the island (R. Valentín, pers. comm.). Another negative

470 effect as a result of the hurricane is the lack of food resources due to the massive exfoliation of

471 food plants. For example, blue-and-yellow macaws, which usually forage high on trees and

472 palms, were observed eating flowers on shrubs as low as $1.5 \mathrm{~m}$ from the ground due to the lack

473 of food. A follow-up study on the status of Psittaciformes after the hurricane is recommended, as

474 it is possible that the negative effects may result in the extirpation of some of the species, 
475 especially those with small population sizes.

476 Many species of Psittaciformes found in the wild in Puerto Rico are vulnerable or

477 endangered in their native range, and introduced populations provide the opportunity to conduct

478 experiments and/or to explore management techniques that otherwise would be impossible to

479 perform in their native habitat, both aspects which may aid in the conservation of Psittaciformes

480 in their native habitats around the world. For example, studying the resources used and

481 ecological functions performed by non-native psittacine species in the novel forests of Puerto

482 Rico may help managers understand how the Puerto Rican amazon will react to such novel

483 habitats and pressures, which is important when considering the level of habitat fragmentation on

484 the island as well as the potential for population increase and expansion by the endemic parrot.

485

486

487

488

489

490

491

492

493

494

495

496

\section{Acknowledgements}

498 We thank Rafael D. Rodríguez, Linda Ortíz and Rebecca Hernández for their help in the field; 
500 Salgado (Puerto Rico Ornithological Society) for providing information on native and invasive

501 psittacines of Puerto Rico. Salgado also helped. We also thank Noramil Herrera, and Alberto

502 Mercado (DNER) for helping in the search of literature resources. Julio A. Salgado of the Puerto

503 Rico Ornithological Society provided assistance in sharing the online form for reporting

504 Psittaciformes in Puerto Rico among different local groups. We also thank Julio Salgado, Yoly

505 Pereira, Pedro Santana, Sonia Longoria, and Dinath Figueroa for permission to use their

506 photographs. Finally, we thank Dr. James D. Ackerman (University of Puerto Rico), Dr. Patricia

507 Gandini (Universidad Nacional de la Patagonia Austral; PeerJ Academic Editor), and Reviewers,

508 including Dr. Donald Brightsmith (Texas A\&M University), Dr. Emiliano Mori (Università degli

509 Studi di Siena), and an anonymous reviewer, for their insightful comments and suggestions on

510 the manuscript.

511 


\section{References}

513 Atyeo WT 1989. Aralichus porrectus (Mégnin \& Trouessart) and related feather mite species

514

515

516

517

518

519

520

521

522

523

524

525

526

527

528

529

530

531

532

533

534

535

536

537

538

539

540

541

542

543

544

545

546

547

548

549

550

551

552

553

554

(Acarina, Pterolichidae) from parrots of the genus Brotogeris Vigors (Aves, Psittacidae).

Systematic Parasitology 14:101-111. DOI: 10.1007/BF00016904.

Avery M, Tillman E 2005. Alien birds in North America: Challenges for wildlife managers. In: Nolte DL, Fagerstone KA eds. 82-89.

Avery ML, Shiels AB 2017. Monk and Rose-Ringed Parakeets. In: Ecology and Management of Terrestrial Vertebrate Invasive Species in the United States. Taylor \& Francis Group, 6000 Broken Sound Parkway NW, Suite 300, Boca Raton, FL 33487-2742: CRC Press, 333-358. DOI: 10.1201/9781315157078-17.

Avery ML, Lindsay JR, Newman JR, Pruett-Jones S, Tilman E 2006. Reducing Monk parakeet impacts to electric utility facilities in South Florida. In: Feare CJ, Cowan DP eds. Advances in Vertebrate Pest Management IV. Furth, 125-136.

Avery ML, Yoder CA, Tillman EA 2008. Diazacon inhibits reproduction in invasive monk parakeet populations. Journal of Wildlife Management 72:1449-1452. DOI: 10.2193/2007391.

Azevedo NP 2014. Detection of Avian Bornavirus, Polyomavirus and Circovirus in biological samples, using PCR and RT-PCR technique, from psittacine bird with different clinical manifestation. Faculdade de Medicina Veterinária e Zootecnia, Universidade de São Paulo. DOI: 10.11606/D.10.2014.tde-07102014-152516.

Blackburn TM, Duncan RP 2001. Establishment patterns of exotic birds are constrained by non-random patterns in introduction. Journal of Biogeography 28:927-939. DOI: 10.1046/j.1365-2699.2001.00597.x.

Blackburn TM, Lockwood JL, Cassey P 2009. Avian invasions: The ecology and evolution of exotic birds. Oxford University Press. DOI: 10.1093/acprof:oso/9780199232543.001.0001.

Blackburn TM, Pysek P, Bacher S, Carlton JT, Duncan RP, Jarosik V, Wilson JRU, Richardson DM 2011. A proposed unified framework for biological invasions. Trends in Ecology \& Evolution 26:333-339. DOI: 10.1016/j.tree.2011.03.023.

Blanco G, Bravo C, Pacifico EC, Chamorro D, Speziale KL, Lambertucci SA, Hiraldo F, Tella JL 2016. Internal seed dispersal by parrots: an overview of a neglected mutualism. PeerJ 4:e1688. DOI: 10.7717/peerj.1688.

Blanco G, Hiraldo F, Tella JL 2017. Ecological functions of parrots: an integrative perspective from plant life cycle to ecosystem functioning. Emu - Austral Ornithology. DOI: 10.1080/01584197.2017.1387031.

Blanco G, Hiraldo F, Rojas A, Dénes FV, Tella JL 2015. Parrots as key multilinkers in ecosystem structure and functioning. Ecology and Evolution 5:4141-4160. DOI: 10.1002/ece3.1663.

Blanco G, Tella JL, Potti J, Baz A 2001. Feather mites on birds: costs of parasitism or conditional outcomes? Journal of Avian Biology 32:271-274. DOI: 10.1111/j.09088857.2001.320310.x.

Briceno C, Surot D, Gonzalez-Acuna D, Javier Martinez F, Fredes F 2017. Parasitic survey on introduced monk parakeets (Myiopsitta monachus) in Santiago, Chile. Revista Brasileira De Parasitologia Veterinaria 26:129-135. DOI: 10.1590/S1984-29612017023. 
555

556

557

558

559

560

561

562

563

564

565

566

567

568

569

570

571

572

573

574

575

576

577

578

579

580

581

582

583

584

585

586

587

588

589

590

591

592

593

594

595

596

597

598

599
Bueno ML, Pennington RT, Dexter KG, Kamino LHY, Pontara V, Neves DM, Ratter JA, Oliveira Filho AT 2017. Effects of Quaternary climatic fluctuations on the distribution of Neotropical savanna tree species. Ecography 40:403-414. DOI: 10.1111/ecog.01860.

Bush ER, Baker SE, MacDonald DW 2014. Global Trade in Exotic Pets 2006-2012. Conservation Biology 28:663-676. DOI: 10.1111/cobi.12240.

Butler CJ 2003. Population Biology of the Introduced Rose-ringed Parakeet Psittacula Krameri in the $U K$.

Camacho-Rodríguez M, Chabert-Llompart J, López-Flores M 1999. Guía para la identificación de las aves exóticas establecidas en Puerto Rico. San Juan: División de Recursos Terrestres, Departamento de Recursos Naturales y Ambientales de Puerto Rico.

Carrete M, Tella JL 2008. Wild-bird trade and exotic invasions: a new link of conservation concern? Frontiers in Ecology and the Environment 6:207-211. DOI: 10.1890/070075.

Cassey P, Blackburn TM, Jones KE, Lockwood JL 2004a. Mistakes in the analysis of exotic species establishment: source pool designation and correlates of introduction success among parrots (Aves: Psittaciformes) of the world. Journal of Biogeography 31:277-284. DOI: 10.1046/j.0305-0270.2003.00979.x.

Cassey P, Blackburn TM, Russell GJ, Jones KE, Lockwood JL 2004b. Influences on the transport and establishment of exotic bird species: An analysis of the parrots (Psittaciformes) of the world. Global Change Biology 10:417-426. DOI: 10.1111/j.1529-8817.2003.00748.x.

Clark FD, Hume GM, Hayes ES 1988. An isolated case of avian pox in a military macaw (Ara militaris mexicana). Companion Animal Practice 2:34-35.

Corlett RT 2013. Where are the Subtropics? Biotropica 45:273-275. DOI: 10.1111/btp.12028.

Dabert J, Mironov SV 1999. Origin and evolution of feather mites (Astigmata). Experimental and Applied Acarology 23:437-454. DOI: 10.1023/A:1006180705101.

Davis MA 2009. Invasion Biology. Oxford: Oxford University Press.

del Hoyo J, Collar NJ, Christie DA, Elliott A, Fishpool LDC 2014. HBW and BirdLife International Illustrated Checklist of the Birds of the World. Volume 1: Non-passerines. Barcelona, Cambridge: Lynx Edicions - BirdLife International.

Departamento de Recursos Naturales y Ambientales de Puerto Rico 2003. Nuevo reglamento para regir la conservación y el manejo de vida silvestre, las especies exóticas y la caza en el Estado Libre Asociado de Puerto Rico.

Done LB, Tamura Y 2014. A presumptive case of Baylisascaris procyonis in a feral greencheeked amazon parrot (Amazona Viridigenalis). Journal of Zoo and Wildlife Medicine 45:157-160. DOI: 10.1638/2012-0263R1.1.

Duncan RP, Blackburn TM, Cassey P 2006. Factors Affecting the Release, Establishment and Spread of Introduced Birds in New Zealand. In: Allen RB, Lee WG eds. Biological Invasions in New Zealand. Ecological Studies. Berlin/Heidelberg: Springer-Verlag, 137154. DOI: 10.1007/3-540-30023-6_9.

Duque-Lazo J, van Gils H, Groen TA, Navarro-Cerrillo RM 2016. Transferability of species distribution models: The case of Phytophthora cinnamomi in Southwest Spain and Southwest Australia. Ecological Modelling 320:62-70. DOI: 10.1016/j.ecolmodel.2015.09.019.

Falcón W, Ackerman JD, Daehler CC 2012. March of the green iguana: Non-native distribution and predicted geographic range of Iguana iguana in the Greater Caribbean Region. IRCF Reptiles and Amphibians 19:150-160. 
600 Falcón W, Ackerman JD, Recart W, Daehler CC 2013. Biology and impacts of Pacific island

601

602

603

604

605

606

607

608

609

610

611

612

613

614

615

616

617

618

619

620

621

622

623

624

625

626

627

628

629

630

631

632

633

634

635

636

637

638

639

640

641

642

643

644 invasive species. 10. Iguana iguana, the green iguana (Squamata: Iguanidae). Pacific Science 67:157-186. DOI: 10.2984/67.2.2.

Fick SE, Hijmans RJ 2017. WorldClim 2: new 1-km spatial resolution climate surfaces for global land areas. International Journal of Climatology 37:4302-4315. DOI: 10.1002/joc.5086.

Forshaw JM 1973. Parrots of the world. Melbourne: Lansdowne Press.

Forshaw JM 2010. Parrots of the World. Princeton: Princeton University Press.

Francisco MR, Lunardi VD, Galetti M 2002. Massive seed predation of Pseudobombax grandiflorum (Bombacaceae) by parakeets Brotogeris versicolurus (Psittacidae) in a forest fragment in Brazil. Biotropica 34:613-615. DOI: 10.1111/j.1744-7429.2002.tb00582.x.

Franklin J 2010. Mapping species distributions: Inference and prediction. Cambridge: Cambridge University Press. DOI: 10.1017/CBO9780511810602.

Freeman EA, Moisen GG 2008. A comparison of the performance of threshold criteria for binary classification in terms of predicted prevalence and kappa. Ecological Modelling 217:48-58. DOI: 10.1016/j.ecolmodel.2008.05.015.

González JA 2003. Análisis preliminar de los daños causados por las aves silvestres a la agricultura en la Amazonía oriental del Perú. In: Bogotá, 370-380.

Gould W, Fevold B, Jiménez ME, Martinuzzi S, Potts G, Solózano M, Ventosa E 2007. Puerto Rico Gap Analysis Project - Final Report. Moscow - San Juan.

Hamrick JL, Murawski DA, Nason JD 1993. The influence of seed dispersal mechanisms on the genetic-structure of tropical tree populations. Vegetatio 108:281-297. DOI: 10.1007/BF00052230.

Hernandes FA, Valim MP, Pedroso LGA 2016. New records of feather mites (Acari: Astigmata) from Pelecaniformes (Aves) in Brazil. Checklist 12:1-25. DOI: 10.15560/12.6.2000.

Hijmans RJ 2017. raster: Geographic data analysis and modeling.

Hijmans RJ, Cameron SE, Parra JL, Jones PG, Jarvis A 2005. Very high resolution interpolated climate surfaces for global land areas. International Journal of Climatology 25:1965-1978. DOI: $10.1002 /$ joc. 1276 .

Hochachka WM, Fink D, Zuckerberg B 2012. Use of citizen science monitoring for pattern discovery and biological inference. In: Gitzen RA, Cooper AB, Millspaugh JJ, Licth DS eds. Design and analysis of long-term ecological monitoring studies. Cambridge, 460-477.

Hope, A. (1968). A simplified Monte Carlo significance test procedure. Journal of the Royal Statistical Society Series B-Statistical Methodology, 30(3), 582-598.

Howe F, Smallwood J 1982. Ecology of seed dispersal. Annual Review of Ecology and Systematics 13:201-228.

Jiménez-Valverde A, Lobo JM 2007. Threshold criteria for conversion of probability of species presence to either-or presence-absence. Acta Oecologica 31:361-369. DOI: 10.1016/j.actao.2007.02.001.

Juniper T, Parr M 1998. Parrots: a guide to the parrots of the world.

Kumschick S, Nentwig W 2010. Some alien birds have as severe an impact as the most effectual alien mammals in Europe. Biological Conservation 143:2757-2762. DOI: 10.1016/j.biocon.2010.07.023.

Lambert MS, Massei G, Yoder CA, Cowan DP 2010. An evaluation of Diazacon as a potential contraceptive in non-native rose-ringed parakeets. Journal of Wildlife Management 74:573581. DOI: $10.2193 / 2008-531$. 
645 Le Louarn M, Couillens B, Deschamps-Cottin M, Clergeau P 2016. Interference competition 646 between an invasive parakeet and native bird species at feeding sites. Journal of Ethology 34:291-298. DOI: 10.1007/s10164-016-0474-8.

649

Liu C, Berry PM, Dawson TP, Pearson RG 2005. Selecting thresholds of occurrence in the prediction of species distributions. Ecography 28:385-393. DOI: 10.1111/j.09067590.2005.03957.x.

650

651

652

653

654

655

656

657

658

659

Lockwood JL 1999. Using taxonomy to predict success among introduced avifauna: Relative importance of transport and establishment. Conservation Biology 13:560-567. DOI: 10.1046/j.1523-1739.1999.98155.x.

Lockwood JL, Brooks TM, McKinney ML 2000. Taxonomic homogenization of the global avifauna. Animal Conservation 3:27-35.

Lockwood JL, Hoopes MF, Marchetti MP 2013. Invasion ecology. John Wiley \& Sons.

Lugo AE 2004. The outcome of alien tree invasions in Puerto Rico. Frontiers in Ecology and the Environment 2:265-273. DOI: 10.1890/1540-9295(2004)002[0265:TOOATI]2.0.CO;2.

Magnino S, Conzo G, Fioretti A, Menna LF, Rampin T, Sironi G, Fabbi M, Kaleta EF 1996. An

660

661

662

663

664

665

666

667

668

669

670

671

672

673

674

675 outbreak of Pacheco's parrot disease in psittacine birds recently imported to Campania, Italy: Isolation of Psittacid Herpesvirus 2. Journal of Veterinary Medicine, Series B 43:631-637. DOI: 10.1111/j.1439-0450.1996.tb00362.x.

Manel S, Williams HC, Ormerod SJ 2001. Evaluating presence-absence models in ecology: the need to account for prevalence. Journal of Applied Ecology 38:921-931. DOI: 10.1046/j.1365-2664.2001.00647.x.

Martens J, Hoppe D, Woog F 2013. Diet and feeding behaviour of naturalised amazon parrots in a European city. Ardea 101:71-76. DOI: 10.5253/078.101.0111.

Mase M, Imada T, Sanada Y, Etoh M, Sanada N, Tsukamoto K, Kawaoka Y, Yamaguchi S 2001. Imported parakeets harbor H9N2 influenza A viruses that are genetically closely related to those transmitted to humans in Hong Kong. Journal of Virology 75:3490-3494. DOI: 10.1128/JVI.75.7.3490-3494.2001.

Menchetti M, Mori E 2014. Worldwide impact of alien parrots (Aves Psittaciformes) on native biodiversity and environment: a review. Ethology Ecology and Evolution 26:172-194. DOI: 10.1080/03949370.2014.905981.

Mooney HA 2005. Invasive Alien Species. Island Press.

676

677

678

679

680

Mori E, Ancillotto L, Menchetti M, Strubbe D 2017. "The early bird catches the nest": possible competition between scops owls and ring-necked parakeets. Animal Conservation 20:463470. DOI: $10.1111 /$ acv.12334.

Mori E, Di Febbraro M, Foresta M, Melis P, Romanazzi E, Notari A, Boggiano F 2013. Assessment of the current distribution of free-living parrots and parakeets (Aves:

681

682

683

684

685

686

687 Psittaciformes) in Italy: a synthesis of published data and new records. Italian Journal of Zoology 80:158-167. DOI: 10.1080/11250003.2012.738713.

Nathan R, Muller-Landau HC 2000. Spatial patterns of seed dispersal, their determinants and consequences for recruitment. Trends in Ecology \& Evolution 15:278-285. DOI: 10.1016/S0169-5347(00)01874-7.

Neu CW, Byers CR, Peek JM 1974. A technique for analysis of utilization-availability data. The Journal of Wildlife Management 38:541-545. DOI: 10.2307/3800887?refreqid=search-

688 gateway:26bc99cd738b37679e645798b8123b20. 
689

690

691

692

693

694

695

696

697

698

699

700

701

702

703

704

705

706

707

708

709

710

711

712

713

714

715

716

717

718

719

720

721

722

723

724

725

726

727

728

729

730

731

Newson SE, Johnston A, Parrott D, Leech DI 2011. Evaluating the population-level impact of an invasive species, ting-necked parakeet Psittacula krameri, on native avifauna. Ibis 153:509_ 516. DOI: 10.1111/j.1474-919X.2011.01121.x.

Norconk MA, Grafton BW, Conklin Brittain NL 1998. Seed dispersal by neotropical seed predators. American Journal of Primatology 45:103-126. DOI: 10.1002/(SICI)10982345(1998)45:1<103::AID-AJP8>3.0.CO;2-\#.

Oberle MW 2000. Puerto Rico's Birds in Photographs. San Juan: Editorial Humanitas.

Olson SL 2015. History, morphology, and fossil record of the extinct Puerto Rican parakeet Psittacara maugei Souance. Wilson Journal of Ornithology 127:1-12. DOI: 10.1676/14020.1 .

Orchan Y, Chiron F, Shwartz A, Kark S 2012. The complex interaction network among multiple invasive bird species in a cavity-nesting community. Biological Invasions 15:429-445. DOI: 10.1007/s10530-012-0298-6.

Orosz SE, Chengappa MM, Oyster RA, Morris PJ, Trock S, Altekruse S 1992. Salmonella enteritidis infection in two species of psittaciformes. Avian Diseases 36:766-769.

Pérez-Rivera RA 1985. Nuevos informes y notas adicionales sobre las aves exóticas que han alcanzado el estado silvestre en Puerto Rico. Science-Ciencia 12:46-48.

Pérez-Rivera RA, Vélez-Miranda M 1980. La proliferación de Psittaciformes en Puerto Rico y el problema que éstos representan. In: San Juan, 115-127. DOI: 10.2307/30243118.

Pérez-Rivera RA, Colón Méndez G, Ríos Estrella W, de Jesús Suárez WL 1985. Aspectos de la ecología del periquito de ala amarilla (Brotogeris versicolurus) en Puerto Rico. ScienceCiencia 12:1-5.

Phillips SJ, Anderson RP, Schapire RE 2006. Maximum entropy modeling of species geographic distributions. Ecological Modelling 190:231-259. DOI: 10.1016/j.ecolmodel.2005.03.026.

Phillips SJ, Dudík M, Schapire RE 2017. Maxent software for modeling species niches and distributions.

QGIS Development Team 2017. QGIS Geographic Information System.

R Core Team 2017. R: A language and environment for statistical computing.

Raffaele HA 1989. A Guide to the Birds of Puerto Rico and the Virgin Islands.

Rafaelle HA 1989. The ecology of native and introduced granivorous birds in Puerto Rico. In Biogeography in the West Indies: past, present, and future: 541-566. Woods, C.A. (Ed.). Gainesville, FL: Sandhill Crane Press

Robinson JM 2001. The dynamics of avicultural markets. Environmental Conservation 28:7685. DOI: $10.1017 / \mathrm{S} 0376892901000078$.

Runde DE, Pitt WC, Foster JT 2007. Population ecology and some potential impacts of emerging populations of exotic parrots. In: Managing vertebrate invasive species 42, 338-360.

http://digitalcommons.unl.edu/nwrcinvasive/42

Sa RCC, Cunningham AA, Dagleish MP, Wheelhouse N, Pocknell A, Borel N, Peck HL, Lawson B 2014. Psittacine beak and feather disease in a free-living ring-necked parakeet (Psittacula krameri) in Great Britain. European Journal of Wildlife Research 60:395-398. DOI: 10.1007/s10344-013-0792-x.

Saikku M 1990. The extinction of the Carolina parakeet. Environmental History Review 14:1-18. DOI: $10.2307 / 3984724$ ?ref=search-gateway:740719859c1e4c91076887de58d83707. 
732

733

734

735

736

737

738

739

740

741

742

743

744

745

746

747

748

749

750

751

752

753

754

755

756

757

758

759

760

761

762

763

764

765

766

767

768

769

770

771

772

773

774

775

776

Sanders NJ, Gotelli NJ, Heller NE, Gordon DM 2003. Community disassembly by an invasive species. Proceedings of the National Academy of Sciences 100:2474-2477. DOI: 10.1073/pnas.0437913100.

Seebens H, Blackburn TM, Dyer EE, Genovesi P, Hulme PE, Jeschke JM, Pagad S, Pysek P, Winter M, Arianoutsou M, Bacher S, Blasius B, Brundu G, Capinha C, Celesti-Grapow L, Dawson W, Dullinger S, Fuentes N, Jaeger H, Kartesz J, Kenis M, Kreft H, Kuehn I, Lenzner B, Liebhold A, Mosena A, Moser D, Nishino M, Pearman D, Pergl J, Rabitsch W, Rojas-Sandoval J, Roques A, Rorke S, Rossinelli S, Roy HE, Scalera R, Schindler S, Stajerova K, Tokarska-Guzik B, van Kleunen M, Walker K, Weigelt P, Yamanaka T, Essl F 2017. No saturation in the accumulation of alien species worldwide. Nature Communications 8. DOI: $10.1038 /$ ncomms 14435.

Smith KF, Behrens M, Schloegel LM, Marano N, Burgiel S, Daszak P 2009. Reducing the risks of the wildlife trade. Science 324:594-595. DOI: 10.1126/science.1174460.

Snyder NFR, McGowan P, Gilardi J, Grajal A (eds.) 2000. Parrots: Status survey and conservation action plan 2000-2004. Cambridge: IUCN.

Snyder NFR, Wiley W, Kepler CB 2007. The parrots of Luquillo: Natural history and conservation of the Puerto Rican parrot. Camarillo: Western Foundation of Vertebrate Zoology. DOI: 10.1086/283697.

Steiner FM, Steiner BCS, VanDerWal J, Reuther KD, Christian E, Stauffer C, Suarez AV, Williams SE, Crozier RH 2008. Combined modelling of distribution and niche in invasion biology: a case study of two invasive Tetramorium ant species. Diversity and Distributions 14:538-545. DOI: 10.1111/j.1472-4642.2008.00472.x.

Strubbe D, Matthysen E 2009a. Experimental evidence for nest-site competition between invasive ring-necked parakeets (Psittacula krameri) and native nuthatches (Sitta europaea). Biological Conservation 142:1588-1594. DOI: 10.1016/j.biocon.2009.02.026.

Strubbe D, Matthysen E 2009b. Establishment success of invasive ring-necked and monk parakeets in Europe. Journal of Biogeography 36:2264-2278. DOI: 10.1111/j.13652699.2009.02177.x.

Sullivan BL, Aycrigg JL, Barry JH, Bonney RE, Bruns N, Cooper CB, Damoulas T, Dhondt AA, Dietterich T, Farnsworth A, Fink D, Fitzpatrick JW, Fredericks T, Gerbracht J, Gomes C, Hochachka WM, Iliff MJ, Lagoze C, La Sorte FA, Merrifield M, Morris W, Phillips TB, Reynolds M, Rodewald AD, Rosenberg KV, Trautmann NM, Wiggins A, Winkler DW, Wong W-K, Wood CL, Yu J, Kelling S 2014. The eBird enterprise: An integrated approach to development and application of citizen science. Biological Conservation 169:31-40. DOI: 10.1016/j.biocon.2013.11.003.

Sullivan BL, Phillips T, Dayer AA, Wood CL, Farnsworth A, Iliff MJ, Davies IJ, Wiggins A, Fink D, Hochachka WM, Rodewald AD, Rosenberg KV, Bonney R, Kelling S 2017. Using open access observational data for conservation action: A case study for birds. Biological Conservation 208:5-14. DOI: 10.1016/j.biocon.2016.04.031.

Swets JA 1988. Measuring the accuracy of diagnostic systems. Science 240:1285-1293. DOI: $10.1126 /$ science. 3287615 .

Symes CT 2014. Founder populations and the current status of exotic parrots in South Africa. Ostrich 85:235-244. DOI: 10.2989/00306525.2014.921866.

Thomsen JB, Edwards SR, Mulliken TA, Network IT 1992. Perceptions, conservation, and management of wild birds in trade. Traffic International. 
777 Wickham H 2011. The split-apply-combine strategy for data analysis. Journal of Statistical 778 Software 40:1-29. DOI: 10.18637/jss.v040.i01.

779 Wickham H 2016. ggplot2: Elegant graphics for data analysis. Cham: Springer. DOI:

$780 \quad 10.1007 / 978-3-319-24277-4$.

781 Yoder CA, Avery ML, Keacher KL, Tillman EA 2007. Use of DiazaCon ${ }^{\mathrm{TM}}$ as a reproductive 782 inhibitor for monk parakeets (Myiopsitta monachus). Wildlife Research 34:8-13. DOI: 783 10.1071/WR06069.

784 Zeileis A, Grothendieck G 2005. zoo: S3 infrastructure for regular and irregular time series. 785 Journal of Statistical Software 14:1-27. DOI: 10.18637/jss.v014.i06. 


\title{
Table $\mathbf{1}$ (on next page)
}

\author{
Introduced Psittaciformes reported in Puerto Rico, their native range, invasiveness and \\ their current status on the island.
}

We list the conservation status in their native range under the Red List (v. 3.1) as least concern (LC), vulnerable (VU), near threatened (NT), and endangered (EN). 'Invasiveness' represent the invasion stage reported outside of Puerto Rico (invasiveness potential) and 'Status' represent the invasion stage at which a species is at the moment in Puerto Rico, according to the categorization scheme by Blackburn et al. (2011; see below for the definitions). 'Pet trade' indicates if the species is known to be currently sold as pet (Y) or unknown (U) in Puerto Rico. Basis of records are from observations by the authors during the surveys, historical records in the literature (prior to 2000), geo-referenced records from online databases, and/or citizen-science records from local birding groups (see electronic supplementary material S1 for the origin of the data). Definitions of invasiveness and status are as follow:

(A) Not transported beyond limits of native range (B1) Individuals transported beyond limits of native range, and in captivity or quarantine (i.e. individuals provided with conditions suitable for them, but explicit measures of containment are in place) (B2) Individuals transported beyond limits of native range, and in cultivation (i.e. individuals provided with conditions suitable for them but explicit measures to prevent dispersal are limited at best) (B3) Individuals transported beyond limits of native range, and directly released into novel environment (C0) Individuals released into the wild (i.e. outside of captivity or cultivation) in location where introduced, but incapable of surviving for a significant period (C1) Individuals surviving in the wild (i.e. outside of captivity or cultivation) in location where introduced, no reproduction (C2) Individuals surviving in the wild in location where introduced, reproduction occurring, but population not self-sustaining (C3) Individuals surviving in the wild in location where introduced, reproduction occurring, and population self-sustaining (D1) Self-sustaining population in the wild, with individuals surviving a significant distance from the original point of introduction (D2) Self-sustaining population in the wild, with individuals surviving and reproducing a significant distance from the original point of introduction (E) Fully invasive species, with individuals dispersing, surviving and reproducing at multiple sites across a greater or lesser spectrum of habitats and extent of occurrence 


\begin{tabular}{|c|c|c|c|c|c|c|}
\hline Species & Common name & Red List & Native range & Invasiveness & Status & Pet trade \\
\hline Agapornis fischeri & Fischer's lovebird & NT & Tanzania & D1-D2 & $\mathrm{C} 0-\mathrm{C} 2$ & $\mathrm{Y}$ \\
\hline Agapornis personatus & Masked lovebird & LC & Tanzania & D1-D2 & $\mathrm{C} 0-\mathrm{C} 2$ & $\mathrm{Y}$ \\
\hline Agapornis roseicollis & Peach-faced lovebirds & LC & Southern Africa & $\mathrm{C} 0-\mathrm{C} 2$ & $\mathrm{C} 0-\mathrm{C} 2$ & $\mathrm{Y}$ \\
\hline Amazona aestiva & Blue-fronted amazon & LC & South America & $\mathrm{C} 0-\mathrm{C} 2$ & $\mathrm{C} 0-\mathrm{C} 2$ & $\mathrm{Y}$ \\
\hline Amazona albifrons & White-fronted amazon & LC & Central America & $\mathrm{C} 0-\mathrm{C} 2$ & $\mathrm{C} 3$ & $\mathrm{Y}$ \\
\hline Amazona amazonica & Orange-winged amazon & LC & South America & D1-D2 & $\mathrm{E}$ & $\mathrm{Y}$ \\
\hline Amazona auropalliata & Yellow-naped amazon & VU & Central America & $\mathrm{C} 0-\mathrm{C} 2$ & B2 & $\mathrm{Y}$ \\
\hline Amazona leucocephala & Cuban amazon & NT & Western Caribbean & B2 & $\mathrm{C} 0-\mathrm{C} 2$ & $\mathrm{U}$ \\
\hline Amazona ochrocephala & Yellow-crowned amazon & $\mathrm{LC}$ & South America & D1-D2 & $\mathrm{C} 0-\mathrm{C} 3$ & $\mathrm{U}$ \\
\hline Amazona oratrix & Yellow-headed amazon & EN & Central America & $\mathrm{C} 0-\mathrm{C} 2$ & $\mathrm{C} 0-\mathrm{C} 3$ & Y \\
\hline Amazona ventralis & Hispaniolan amazon & VU & Hispaniola & $\mathrm{C} 0-\mathrm{C} 2$ & $\mathrm{C} 0-\mathrm{C} 3$ & $\mathrm{U}$ \\
\hline Amazona viridigenalis & Greencheeked amazon & EN & Mexico & $\mathrm{C} 0-\mathrm{C} 2$ & $\mathrm{C} 3$ & Y \\
\hline Anodorhynchus hyacinthinus & Hyacinth macaw & VU & South America & B2 & B2 & Y \\
\hline Ara ararauna & Blue-and-yellow macaw & $\mathrm{LC}$ & South America & $\mathrm{C} 0-\mathrm{C} 2$ & $\mathrm{E}$ & Y \\
\hline Ara chloropterus & Red-and-green macaw & $\mathrm{LC}$ & South America & B2 & $\mathrm{C} 0-\mathrm{C} 2$ & Y \\
\hline Ara macao & Scarlet macaw & $\mathrm{LC}$ & C.-S. America & B2 & $\mathrm{C} 0-\mathrm{C} 3$ & Y \\
\hline Ara militaris & Military macaw & VU & South America & $\mathrm{C} 0-\mathrm{C} 2$ & $\mathrm{C} 0-\mathrm{C} 2$ & Y \\
\hline Aratinga (Nandayus) nenday & Nanday conure & $\mathrm{LC}$ & Northern S. America & D1-D2 & $\mathrm{C} 0-\mathrm{C} 2$ & Y \\
\hline
\end{tabular}




\begin{tabular}{|c|c|c|c|c|c|}
\hline Aratinga jandaya & Jandaya conure & LC & Brazil & B2 & B2 \\
\hline Aratinga solstitialis & Sun conure & EN & Brazil, Guyana & $\mathrm{C} 0-\mathrm{C} 2$ & B2 \\
\hline Brotogeris versicolurus & White-winged parakeet & LC & South America & $\mathrm{E}$ & $\mathrm{E}$ \\
\hline Cacatua alba & White-crested cockatoo & EN & Indonesia & $\mathrm{C} 0-\mathrm{C} 2$ & $\mathrm{C} 0-\mathrm{C} 2$ \\
\hline Cacatua galerita & Sulfur-crested cockatoo & LC & Australasia, Indonesia & D1-D2 & $\mathrm{C} 0-\mathrm{C} 2$ \\
\hline Cacatua goffiniana & Goffin's corella & NT & Indonesia & D1-D2 & $\mathrm{C} 0-\mathrm{C} 2$ \\
\hline Cacatua moluccensis & Salmon-crested cockatoo & VU & Indonesia & B2 & $\mathrm{C} 0-\mathrm{C} 2$ \\
\hline Cacatua sulfurea & Yellow-crested cockatoo & $\mathrm{CR}$ & Timor-Leste, Indonesia & B2 & B2 \\
\hline Eupsittula (Aratinga) canicularis & Orange-fronted conure & LC & Central America & B2 & $\mathrm{E}$ \\
\hline Eupsittula (Aratinga) pertinax & Brown-throated conure & LC & Aruba, C.-S. America & $\mathrm{C} 0-\mathrm{C} 2$ & $\mathrm{C} 0-\mathrm{C} 2$ \\
\hline Forpus passerinus & Green-rumped parrolet & LC & Northern S. America & D1-D2 & B2 \\
\hline Melopsittacus undulatus & Budgerigar & LC & Australia & $\mathrm{C} 0-\mathrm{C} 2$ & $\mathrm{C} 0-\mathrm{C} 2$ \\
\hline Myiopsitta monachus & Monk parakeet & LC & South America & E & $\mathrm{E}$ \\
\hline Nymphicus hollandicus & Cockatiel & LC & Australia & $\mathrm{C} 0-\mathrm{C} 2$ & $\mathrm{C} 0-\mathrm{C} 2$ \\
\hline Poicephalus senegalus & Senegal & LC & Africa & B2 & $\mathrm{C} 0-\mathrm{C} 2$ \\
\hline Psephotus haematonotus & Red-rumped parrot & LC & Australia & B2 & B2 \\
\hline Psittacara (Aratinga) chloropterus & Hispaniolan conure & VU & Hispaniola & $\mathrm{C} 0-\mathrm{C} 2$ & $\mathrm{C} 0-\mathrm{C} 3$ \\
\hline Psittacara (Aratinga) erythrogenys & Red-masked conure & NT & Ecuador, Peru & D1-D2 & D2 \\
\hline Psittacara mitratus & Mitred conure & LC & South America & B2 & $\mathrm{C} 0-\mathrm{C} 2$ \\
\hline Psittacula krameri & Roseringed parakeet & $\mathrm{LC}$ & Africa and Asia & E & $\mathrm{C} 0-\mathrm{C} 2$ \\
\hline
\end{tabular}




\begin{tabular}{|c|c|c|c|c|c|c|}
\hline Psittacus erithacus & African grey parrot & $\mathrm{EN}$ & Africa & $\mathrm{C} 0-\mathrm{C} 2$ & B2 & $\mathrm{Y}$ \\
\hline Psittacus timneh & Timneh parrot & $\mathrm{EN}$ & West Africa & B2 & B2 & $\mathrm{Y}$ \\
\hline Pyrrhura hoffmanni & Sulphur-winged parakeet & LC & Central America & B2 & $\mathrm{C} 0-\mathrm{C} 2$ & $\mathrm{Y}$ \\
\hline Pyrrhura molinae & Green-cheeked conure & LC & South America & B2 & $\mathrm{C} 0-\mathrm{C} 2$ & $\mathrm{Y}$ \\
\hline Pyrrhura perlata & Crimson-bellied conure & $\mathrm{VU}$ & South America & B2 & B2 & $\mathrm{Y}$ \\
\hline Pyrrhura roseifrons & Rose-fronted parakeet & LC & South America & B2 & $\mathrm{C} 0-\mathrm{C} 2$ & $\mathrm{U}$ \\
\hline Thectocercus acuticaudatus & Blue-crowned parakeet & NA & South America & $\mathrm{C} 0-\mathrm{C} 2$ & $\mathrm{C} 0-\mathrm{C} 2$ & $\mathrm{U}$ \\
\hline Trichoglossus haematodus & Rainbow lorikeet & $\mathrm{LC}$ & Australasia, Indonesia & $\mathrm{C} 0-\mathrm{C} 2$ & B2 & $\mathrm{Y}$ \\
\hline
\end{tabular}




\section{Table 2 (on next page)}

Occurrence locations and MaxEnt summary statistics for predicting the distribution of four species of Psittaciformes in Puerto Rico.

Total occurrence locations used for the model (Occ. loc.), and the subset of occurrence locations for Puerto Rico given in parentheses. Model performance for predicting the distribution of four species of Psittaciformes in Puerto Rico given by the training ( $80 \%$ occurrence points) and test (20\% occurrence points) Area Under the ROC Curve (AUC), and the Maximum training Sensitivity plus Specificity presence-absence threshold (MS+ST). Values given are the mean $( \pm S D)$ based on ten replicates. 


\begin{tabular}{lcccc}
1 & & & \\
\hline & Occ. loc. & Training AUC & Test AUC & MS+ST \\
\hline Brotogeris versicolurus & $1,119(557)$ & $0.91( \pm 0.001)$ & $0.92( \pm 0.006)$ & $0.27( \pm 0.024)$ \\
Myopsitta monachus & $15,985(707)$ & $0.82( \pm 0.001)$ & $0.82( \pm 0.004)$ & $0.30( \pm 0.031)$ \\
Psittacara erythrogenys & $1,392(42)$ & $0.94( \pm 0.002)$ & $0.94( \pm 0.003)$ & $0.20( \pm 0.036)$ \\
Eupsittula canicularis & $3,707(55)$ & $0.84( \pm 0.001)$ & $0.84( \pm 0.005)$ & $0.27( \pm 0.014)$ \\
\hline \hline
\end{tabular}

2 


\section{Figure 1}

Some of the species of Psittaciformes that occur in the wild in Puerto Rico, and Hurricane Maria-related mortality.

A pair of blue-and-yellow macaws (Ara ararauna) in their nest on Roystonea borinquena (Aracaceae; a), an orange-winged amazon (Amazona amazonica) eating palm fruits (Aracaceae; b), an orange-fronted parakeet (Eupsittula canicularis) foraging on seeds of Lagerstroemia speciosa (Lythraceae; c), a monk parakeet (Myiopsitta monachus) eating the flower buds of Bucida buceras (Combretaceae; d), a white-winged parakeet (Brotogeris versicolurus) eating flower buds (Fabaceae; e), and six out of dozens of white-winged parakeets that died during Hurricane Maria in 2017 (f). Photo credits: Yoly Pereira (a), Julio Salgado (b, e), Pedro Santana (c), Sonia Longoria (d), Dinath Figueroa (f). 

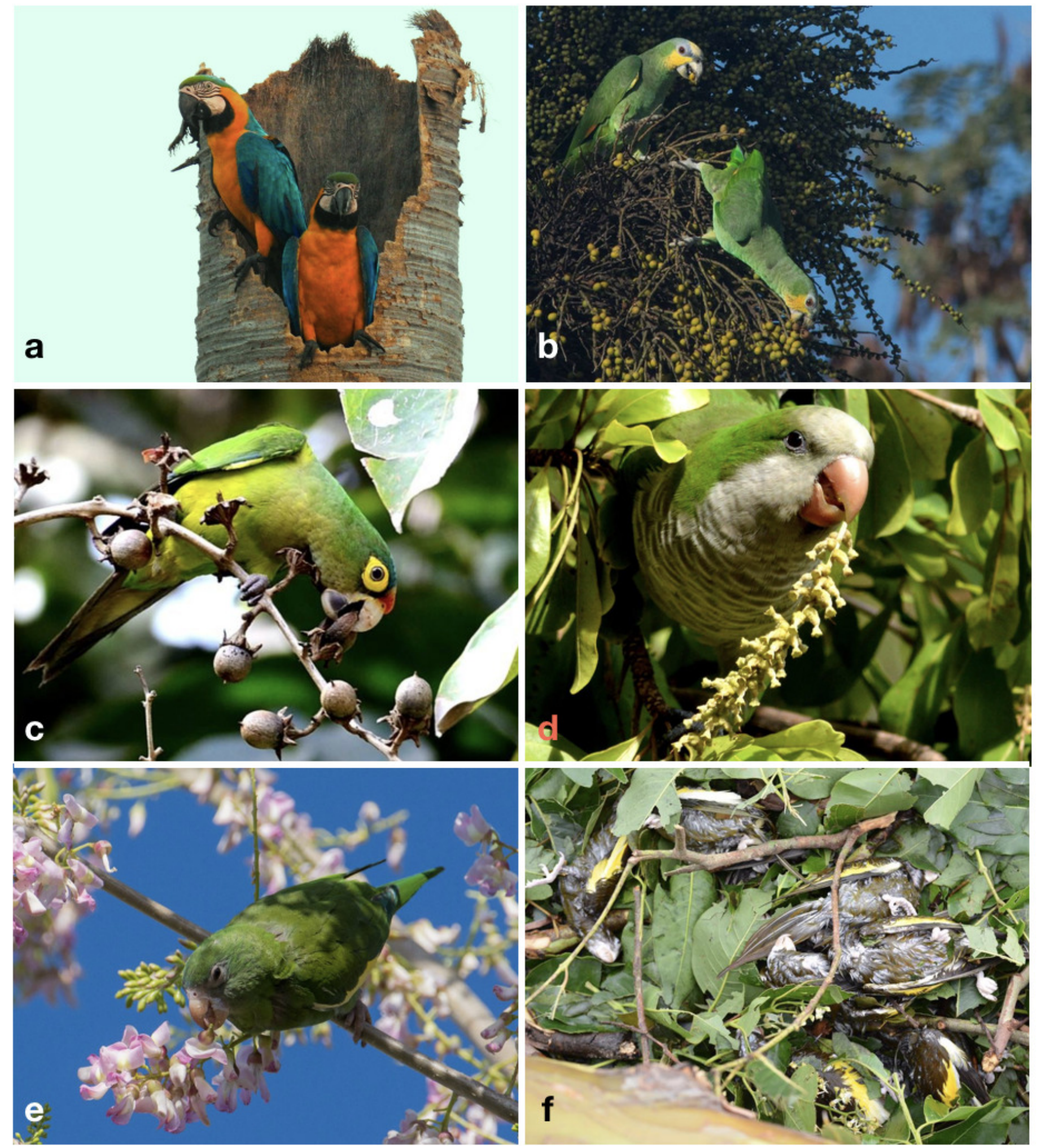
Figure 2

Sighting trends of different species of Psittaciformes in Puerto Rico showing population increase $(a, d, g, j)$, stable populations $(b, e, h)$ and population decrease $(c, f, i)$.

Island-wide sighting trends were calculated as the sum of the mean number of birds counted per year/municipality (data from Ebird). Grey shading indicates the $95 \% \mathrm{Cl}$ based on the local weighted scatterplot smoothing (loess). 


\section{Increasing}

a

White-winged parakeet

(Brotogeris versicolurus)

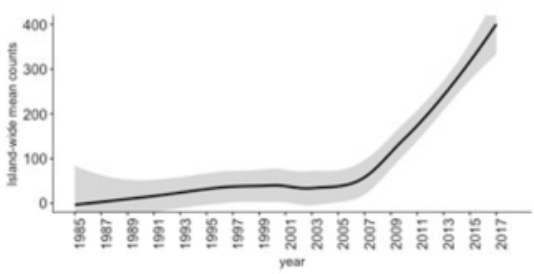

d

Monk parakeet (Myopsitta monachus)

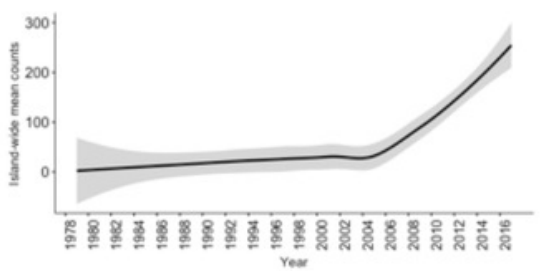

g

Red-masked conure

(Psittacara (Aratinga) erythrogenys)

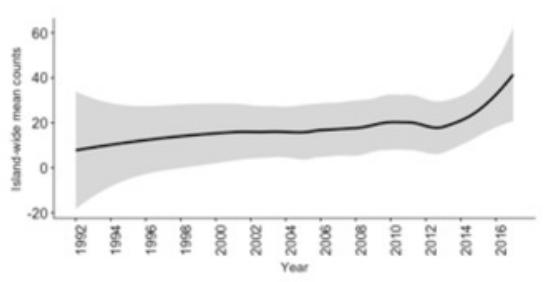

j

Orange fronted parakeet (Eupsittula (Aratinga) canicularis)

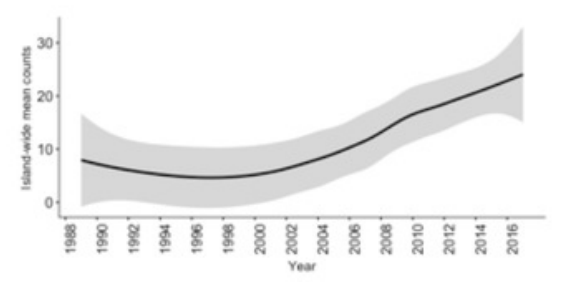

\section{Stable}

b

Orange-winged amazon

(Amazona amazonica)

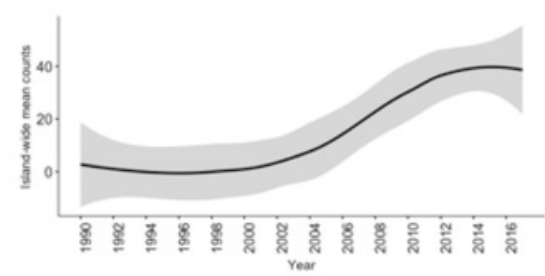

e

Blue-and-yellow macaw

(Ara aranaura)

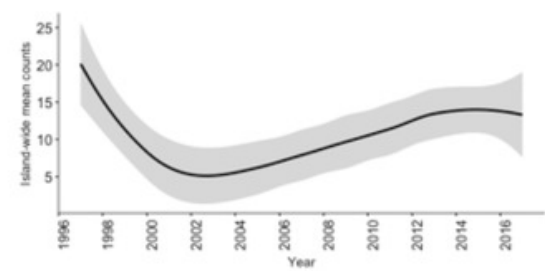

h

White-crested cockatoo

(Cacatua alba)

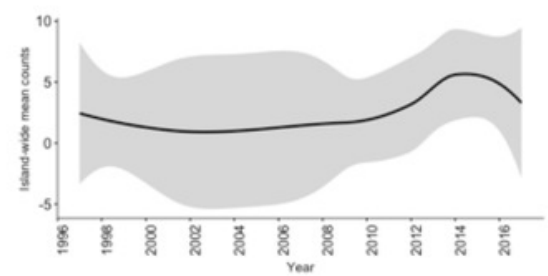

\section{Decreasing}

C

Green-cheeked amazon

(Amazona viridigenalis)

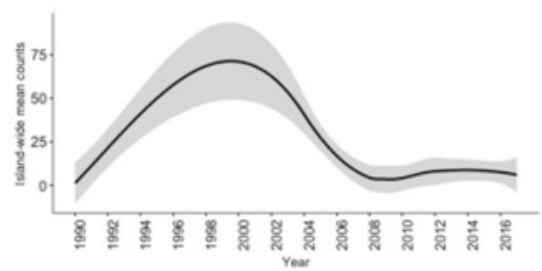

f

White-fronted amazon

(Amazona albifrons)

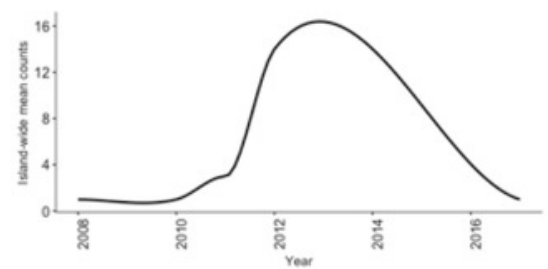

i

Rose-ringed parakeet

(Psittacula krameri)

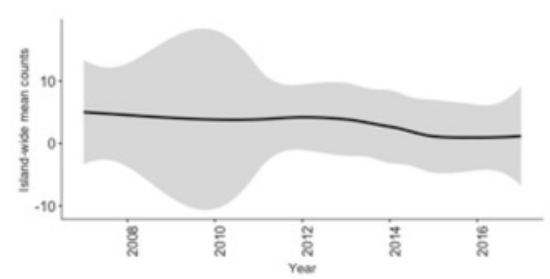




\section{Figure 3}

Distribution of 25 species of Psittaciformes in Puerto Rico, depicted by the different colors.

Records originated from observations made by the authors, online databases, and reports from local birding groups (see methods).

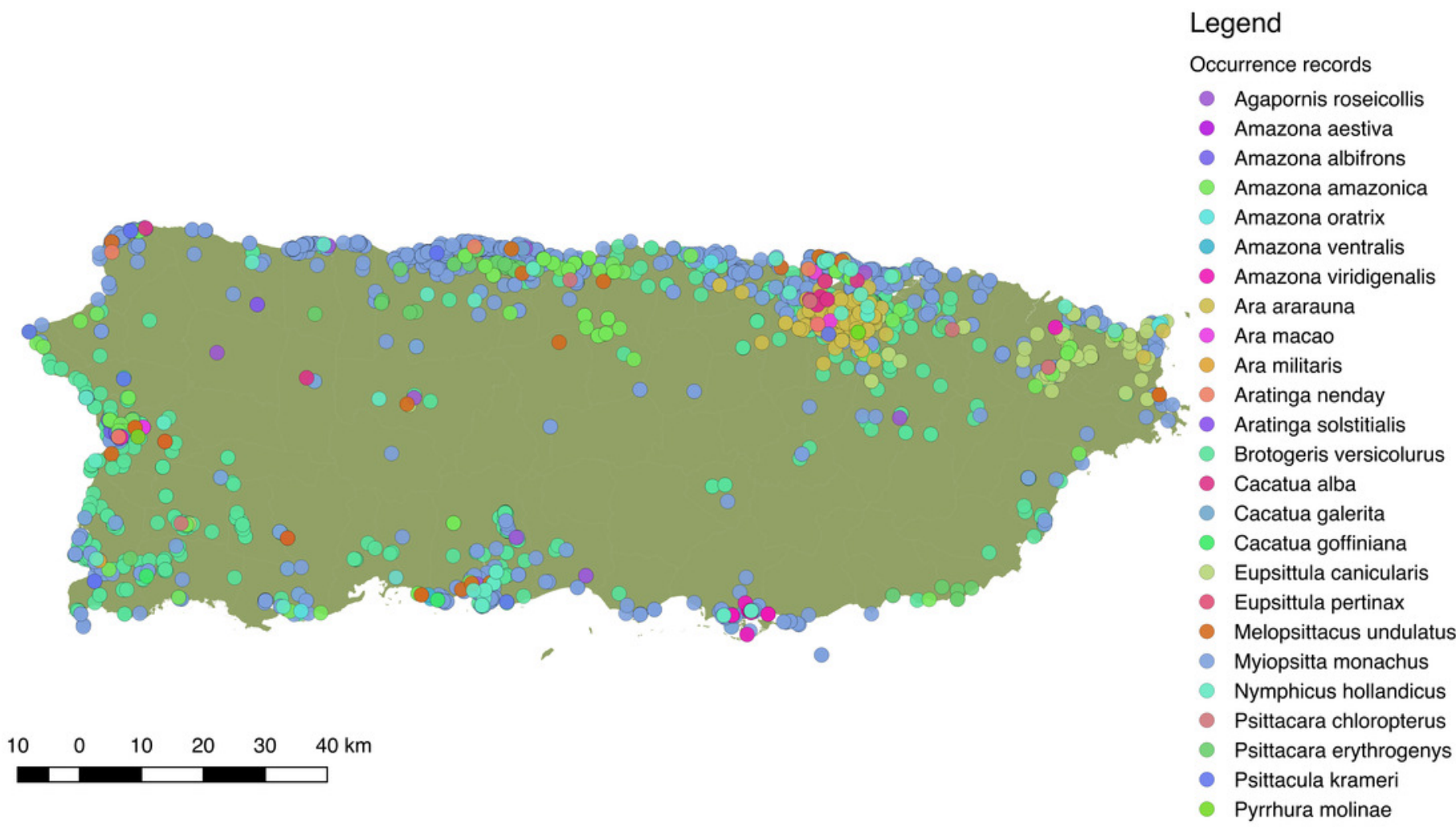




\section{Figure 4}

Current distribution of Psittaciformes in Puerto Rico whose populations are increasing (top maps in each panel) and the predicted distribution of the species based on the maximum entropy model (MaxEnt, bottom maps in each panel).

Warmer colors depict higher suitability. 
a

White-winged parakeet (Brotogeris versicolurus)
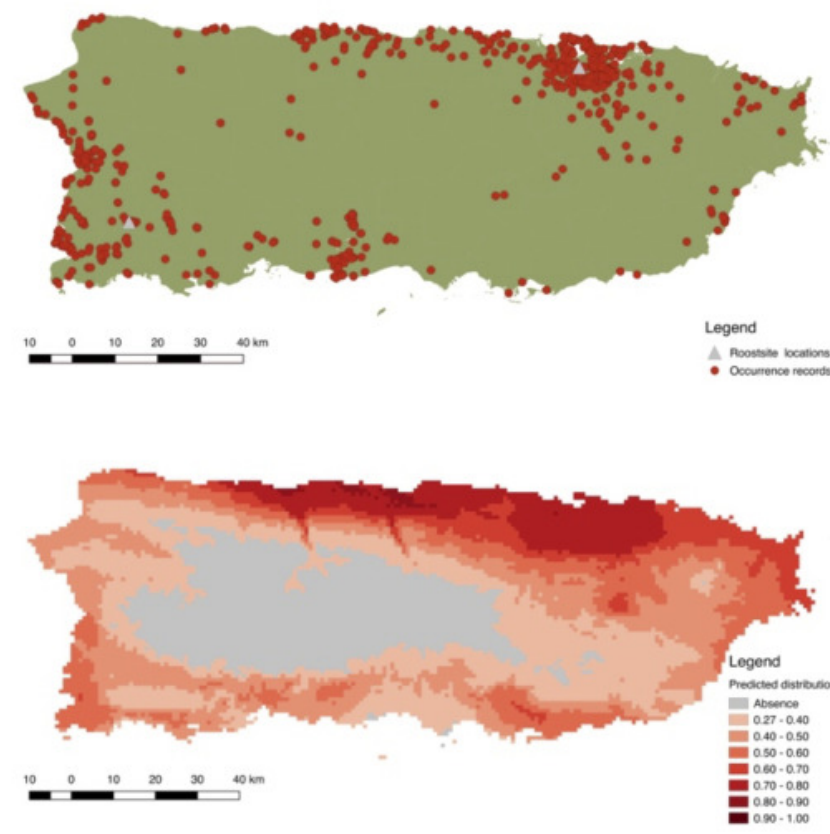

C

Red-masked conure

(Psittacara (Aratinga) erythrogenys)
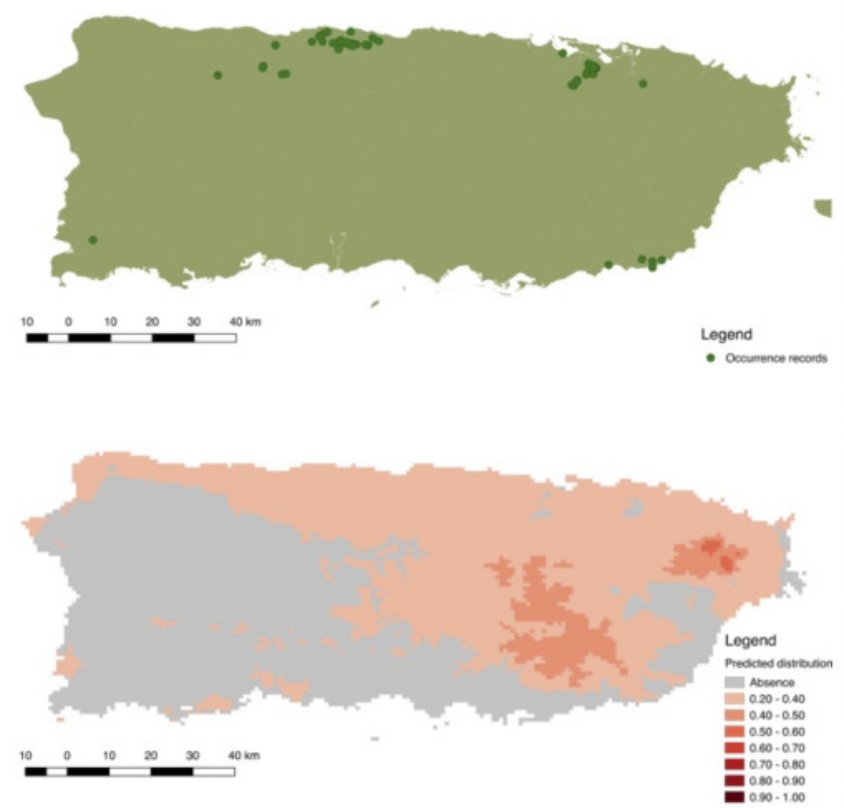

b

Monk parakeet
(Myopsitta monachus)
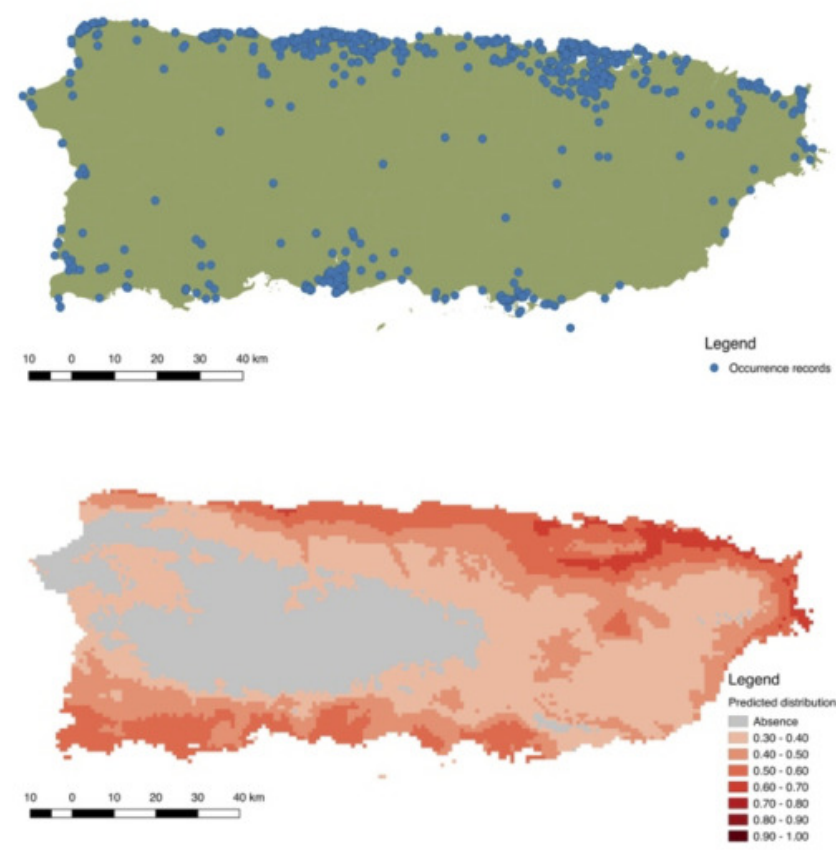

d

Orange fronted parakeet

(Eupsittula (Aratinga) canicularis)

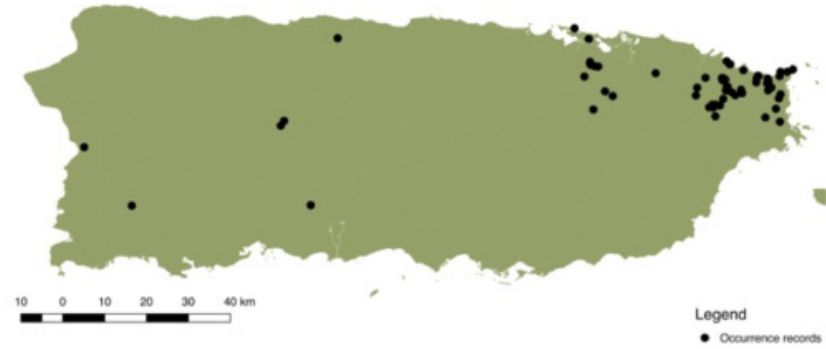

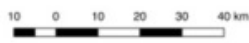

